\title{
How to Evaluate Interactions during a Debate of Ideas
}

\author{
Zeineb Zerai ${ }^{1}$, Rim Mekni $^{2}$ \\ ${ }^{1}$ University of Manouba, Manouba, Tunisia \\ ${ }^{2}$ University of Jendouba, Jendouba, Tunisia \\ Email: zeraizizou@yahoo.fr
}

How to cite this paper: Zerai, Z., \& Mekni, R. (2017). How to Evaluate Interactions during a Debate of Ideas. Creative Education, 8, 539-548.

https://doi.org/10.4236/ce.2017.84042

Received: March 2, 2017

Accepted: April 21, 2017

Published: April 27, 2017

Copyright (c) 2017 by authors and Scientific Research Publishing Inc. This work is licensed under the Creative Commons Attribution International License (CC BY 4.0).

http://creativecommons.org/licenses/by/4.0/

\begin{abstract}
The idea of a debate of ideas is part of an innovative conception of the teaching/learning system at school, in which knowledge is developed with the help of peers and the teacher. The debate of ideas first appears as a situation of verbalization about action intended to make aware of the task to be carried out and the instructions that characterize it. To evaluate its effects, we will take data from the experimentation of Zerai (2009) and give us a triangulation between the result and the score of the encounters, quantitative data (balls played, balls conquered, etc.) and a qualitative data: the roadmap. We will try to test the contributions of peer interactions. The methodology used was to observe and retrieve data on a group of Tunisian second-year girls from Thala Secondary High School in a handball cycle. In this group of twenty girls, we organized four sub-groups to form the teams. The chosen triangulation allows an indirect measure of the effectiveness of the debate of ideas. The performance of the team (the ratio of shots to the number of goals) appears very quickly as a trigger for concertation between the players. The observation made collectively on the losses of the ball will also, very quickly generate reactions. The roadmap relies more on the planned strategy and the changes of roles within the team that it implies. In conclusion, comparing the selected indicators provides a realistic way of assessing the adequacy between interactions and progress in the game. This type of work emphasizes the time needed to succeed. One of the achievements of the research in didactics of collective sports at school is that the learning of a game can not be conceived without an important practice. For pupils, a real learning in collective sports games lies, in situations of problem gambling, to observe, to extract, to evaluate the information more and more relevant to reduce the time of analysis, and thus of decision to act on the opposition reports.
\end{abstract}

\section{Keywords}

Team Sport, Tactics, Debate of Ideas, Evaluation, Roadmap 


\section{Introduction}

In a learning activity and in a cognitivist perspective, trainees, actors in their own training, develop a self-regulation activity consisting in comparing the goal put in perspective with the result achieved, then analyzing the reasons for the failure and/or success. This comparison makes it possible to change the planning, the selection of the actions and the motor skills used. The debate of ideas constitutes a central part of a constructivist conception of the learning of collective sports. It consists, after a sequence played and with an encrypted feedback, feedbacks provided or not by the teacher in a discussion intended to evolve or not the planned strategy by analyzing the tactics applied and the result of the match.

This idea of the debate of ideas is part of an innovative conception of the teaching/learning system at school, in which knowledge is elaborated with the help of peers and the teacher. The debate of ideas first appears as a situation of verbalization about action intended to make aware of the task to be carried out and the instructions that characterize it. Studies (Gréhaigne, Billard, \& Laroche, 1999; Chang, 2006) on the notion of "debate of ideas" supplemented this notion by including observation and emphasizing the need to take a step back from the action. Verbal exchanges in the context of the debate of ideas make it possible to make present and to share individual and past experiences and information, thus creating a universe of references available which include: data, reminders, exchanges of information and information, experiences. Communication is, according to Giordan (1983), one of the means for expressing and opposing the "pre-scientific" representations and attitudes of children. It is also an opportunity to share an interpretative horizon. According to Casetti, Lumbelli \& Wolf (1981) the debate is an organized discussion, a confrontation of opinions about a particular object but which takes place in a prefixed framework. Thus, the length of the debate, the duration, the number of participants and the object of the exchange are thus partly predetermined. The debate thus arises both from the discussion by its descriptive and argumentative character and from the interview by its media character.

To this end, we will take data from the Zerai experiment (2016) and give an indirect analysis of the discussions between the students used in this research. From a triangulation between the result and the score of the meetings, quantitative data (balls played, balls conquered, etc.) and a qualitative data: the roadmap, we will try to test the contributions of interactions between peers.

\section{Methodology}

The game, which emphasizes the notions of opposition/cooperation, poses real problems for the formative evaluation. The match with its opposition relations, classically located at the end of the lesson, as the moment of application of what has been seen during the lesson, will take on a central importance here. The introduction of this triangulation should allow us to better analyze the effects of the idea debate. 


\subsection{Population}

The methodology used consisted of observing a group of Tunisian second-year girls from Thala Secondary High School in a handball cycle. The girls are between the ages of 15 and 16 . We chose this level because Tunisian girls begin to play collective sports in high school. In this group of twenty girls, we organized four subgroups to constitute the two teams (A and B) who will play and ten girls for the observation tasks for which they were trained during the two weeks preceding the Beginning of the work cycle. The total duration of the game in the three tests was $30 \mathrm{~min}$ ( 2 half-time $15 \mathrm{~min}$ ) to allow a total investment of girls.

Group A (control) consisted of five players and five observers. The girls were confronted with the "training + instructions" modality. The instructions, in the form of rules of effective actions, were given at the beginning and during the game. There was no dialogue between the players and the observers, who only looked at the figures for the research. Group B (experimental) was also composed of five players and five observers and they were confronted with the modality "training + instructions + debate of ideas + roadmap". The debate of ideas took place between each situation of play.

Assessment and observation tools

The observation sheets were constructed from the individual evaluation sheet proposed by Gréhaigne, Billard \& Laroche (1999). After the first test, a verification of the accuracy of the readings was performed between the live data and the deferred data from the videotape. There were almost no errors, the game being relatively slow and easy to observe. The written data of the roadmaps, defining the chosen strategy and the projects in progress were identified and analyzed.

\subsubsection{Results and Score of the Meetings}

The fundamental rules of all opposition games constitute the central core of rules and the legal framework "guaranteeing both the essence of the activity and the physical health of the practitioners" (Conquet \& Devaluez, 1986: p. 93). To score in handball, it's necessary to penetrate the ball in two vertical targets, extending to the ground, at the ends of a large ground. Targets are narrower in width than the width of the terrain and can be kept. An indication that is important depending on the value of the goalkeeper.

The result of a meeting is essential in the logic of collective sports where one moves from equal opportunities to inequality of outcome (Jeu, 1977) (Table 1).

\subsubsection{Quantitative Data: BP; LB; BC}

In order to obtain data on what actually happens, we have analyzed the different game sequences (Dugrand, 1985, Gréhaigne, Caty, \& Wallian, 2004, Gréhaigne,

Table 1. Example of observation tools for shots and goals.

\begin{tabular}{lllllll}
\hline \multicolumn{7}{c}{ Team A } \\
\hline & P1 & P2 & P3 & P4 & Total \\
\hline Shots/Goals & & & & & & \\
\hline
\end{tabular}


Godbout, \& Bouthier, 1999; Gréhaigne, Wallian, \& Godbout, 2005). These can be defined as "ball exchanges" between players from the possession of the ball to its loss (goal or ball to the opponent) by the team. For example, in a team of four players, all entries in possession of the ball are recorded within each team. In a nutshell, we record events of the game by specifying two elements: conquered balls (ball taken from the opponent) or lost balls (balloon taken by the opponents).

These quantitative data make it possible to obtain, indirectly, valuable information on the team's network of skills. This is constituted by the relationships between players within a team. Indeed, in each team are established a distribution of the tasks required by some, conflicts, or a tacit distribution of roles and functions generating a network of skills (Table 2).

\subsubsection{Qualitative Data: The Roadmap}

It is a tool used to put into perspective strategies and an approach to guide students' work. Here, spontaneous observation is no longer sufficient to transform the game. It is therefore necessary to take a certain number of guarantees to build another framework of reference in order to build a common culture of information to be taken into account by the players. How to proceed?

From a short game sequence (play/shot or goal), two different observers located at distinct locations look at this sequence. Then, the two observers compare their observations (common points, differences) between them; meanwhile, their partners discuss what they think they have done. Then a debate is instituted between all the parties (observers and players). More often than not, it leads to a consensus in writing, acceptable to everyone and thus leading to a valorization of the information gathered.

\section{Results}

We will now present the main results obtained with the class of the Thala high school.

\subsection{The Shots and Goals and the Result of the Meetings}

A first datum "one won" or "they have lost" represents the translation of the fundamental problem of the collective sports. This consists, first of all, in the self-organization of a group confronted with another group with antagonistic interests in order to achieve a common goal (constituted by a target) by means

Table 2. Example of observation tools for quantitative data: PB, CB, and LB.

\begin{tabular}{cccccc}
\hline \multicolumn{5}{c}{ Team } \\
& $\mathrm{Pa} 1$ & $\mathrm{~Pa} 2$ & $\mathrm{~Pa} 3$ & $\mathrm{~Pa} 4$ & Total \\
\hline $\begin{array}{c}\text { Played balls } \\
\text { Conquered balls } \\
\text { Lost Balls }\end{array}$ & & & \\
\hline
\end{tabular}


of a common strategy. This fundamental problem of collective sports could thus be clarified: in an opposition report (Deleplace, 1979) it is a question of coordinating its actions in order to recover, preserve, advance the ball with the aim of bringing it in the mark area and mark (Table 3 ).

The score also gives indications of the balance of forces involved because it is not the same as losing or winning 2 to 1,5 to 4 or 11 to 2 . Shooting 34 times on goal for 5 goals is very revealing of a difficulty to conclude compared to 15 shots pure 4 goals. This also results in a lot of ball loss finally; this allows having a first idea on the network of skills in each team with who shoots and who scores in each team.

\subsection{Played Balls, Conquered Balls and Lost Balls}

The game volume expresses the ability of the player or team to play a full game in the quantitative sense of the term. He reports his presence and his activity in the confrontation. It translates simply by the number of balls played (PB) in a specific balance of forces (Table 4).

Depending on the number of PBs, you can pinpoint the player who makes the commitments and the touchdowns, the one who loses balls or gives bullets to the team by regaining possession of the ball. One can also spot precisely who leads the game by touching many balls and losing little; it is generally the best player of the team. This set makes it possible to obtain a first idea between the strategy adopted and the opposition relations involved and to further refine the network of skills of each team. To evolve, this division of tasks requires time; the establishment of a balance sheet for each player in order to optimize the contributions of all to the collective and while making the community allows everyone to improve.

Table 3. Example of shots and goals during the first meeting.

\begin{tabular}{ccccccccccc}
\hline & \multicolumn{4}{c}{ Team A } & \multicolumn{1}{c}{ Team B } \\
\cline { 2 - 11 } & $\mathrm{Pa} 1$ & $\mathrm{~Pa} 2$ & $\mathrm{~Pa} 3$ & $\mathrm{~Pa} 4$ & Total & $\mathrm{Pb} 1$ & $\mathrm{~Pb} 2$ & $\mathrm{~Pb} 3$ & $\mathrm{~Pb} 4$ & Total \\
\hline Shots/Goals & $2 / 0$ & $2 / 0$ & $4 / 1$ & $7 / 3$ & $\mathbf{1 5 / 4}$ & $8 / 1$ & $7 / 0$ & $8 / 1$ & $11 / 3$ & $\mathbf{3 4 / 5}$ \\
\hline
\end{tabular}

Table 4. Example of encrypted data at the first meeting.

\begin{tabular}{ccccccccccc}
\hline & \multicolumn{3}{c}{ Team A } & \multicolumn{7}{c}{ Team B } \\
\cline { 2 - 10 } & $\mathrm{Pa} 1$ & $\mathrm{~Pa} 2$ & $\mathrm{~Pa} 3$ & $\mathrm{~Pa} 4$ & Total & $\mathrm{Pb} 1$ & $\mathrm{~Pb} 2$ & $\mathrm{~Pb} 3$ & $\mathrm{~Pb} 4$ & Total \\
\hline $\begin{array}{c}\text { Played balls } \\
\begin{array}{c}\text { Conquered } \\
\text { balls }\end{array}\end{array}$ & 40 & 31 & 43 & 70 & 184 & 49 & 53 & 47 & 70 & 219 \\
Lost Balls & 15 & 10 & 17 & 19 & $\mathbf{6 1}$ & 12 & 9 & 8 & 13 & 42 \\
\hline
\end{tabular}

Some definitions: balls played: any ball touched; Ball conquered: ball intercepted, ball recovered on fault (key, free jet etc); Lost Ball: A ball that results in a stoppage of play, foul or recovery by the opponent. 
The defensive index relates the number of balls conquered and the number of balls lost. It shows the players' ability to recover and retain the ball (BC/BL). This index varies from zero when no ball is conquered to 1 if the number of balls conquered is equal to the number of lost balls and greater than 1 if the number of balls conquered is greater than the number of balls lost. Over a longer period, this ratio between conquered and lost balls underlines the effectiveness of Group $B$ in recovering and retaining the ball (Figure 1 ). Due to an effective placement in attack and defense, this ratio is greater than 3 during the 10th lesson. As for her, team A (control group) sees its report declined from the 1 st to the 10th lesson (Zerai, 2006).

\subsection{The Roadmap for a Team}

The wording of the game is in itself a new experience and talking about the game also helps to build it. However, if the player can be performing at the level of the motor skills or the intellectual and technical activities covering his activity, he may have real difficulties in putting this activity into words. Defining objects, their properties, relationships, transformations, and meeting the communication requirements expected in the validation process takes a lot of effort. During the debate of ideas, the player is led to express himself to say "where and how it happens" in a very general way, with exchanges of words between him and his partners. The limits for dealing with these events are time, complexity, and consistency between signals and responses.

In a collective sport, a common theme is to have intentions when drawing up a roadmap. The setting up of this theme very often provokes the proposal of circulation of the ball and fanciful players. We therefore prefer the theme of "actions in project" which highlights the interaction between subject and environment in any decision-making or action project related to the need to propose a realistic "roadmap".

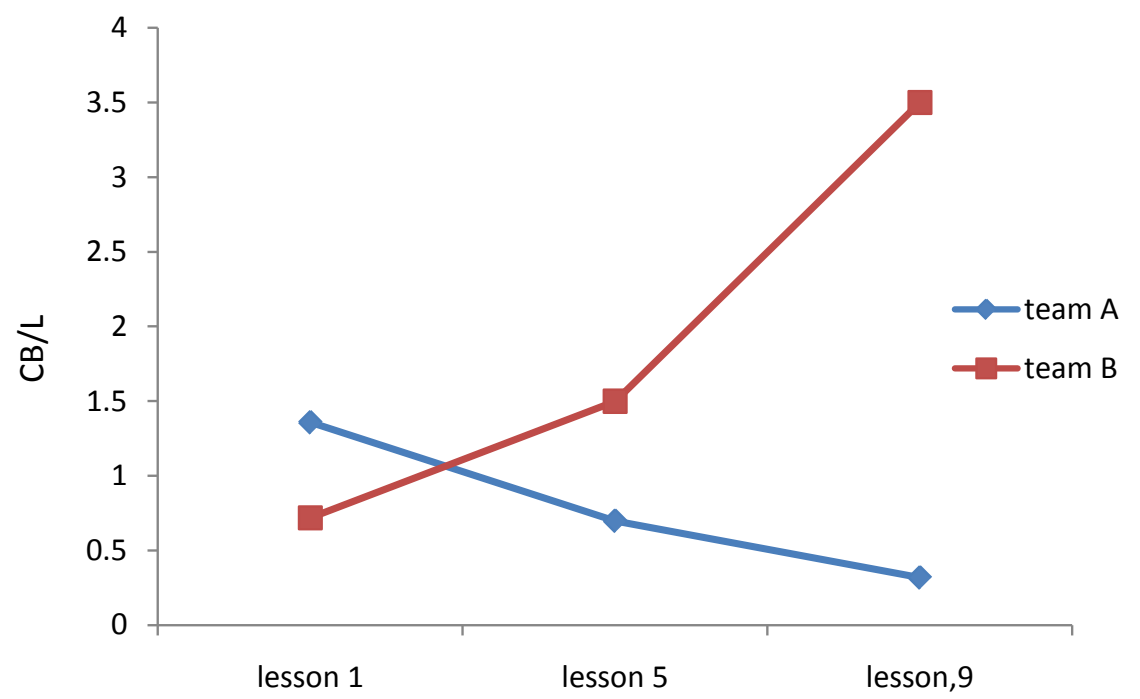

Figure 1. Relationship between conquered balls and lost balls on a 12-lesson work cycle. 
A roadmap is, therefore, a pedagogical tool that acts out the decisions taken during the debate of ideas. In order to make it work better, for a defined time, two observers gather information about the two teams involved. At the first stop of play, the observers communicate the information to their team on their own production as well as on the organization of the opposing team. The group records information links it and makes decisions for the next sequence.

For example, for a team that has difficulty with the circulation of the ball, it can temporarily decide to try to recover the ball as close as possible to the opposing goal to the rear space of the attacking team and just after the recovery of shoot As soon as possible.

This decision must become quantitatively observable in order to measure and objectify the chosen strategy. Then the two observers enter to play and, in fact, become the privileged actors of the decisions taken. Two new observers provide new data and the process is repeated.

To assess the adequacy between the decisions made and the game produced during the sequence, it is enough to cross the result of the meeting, the number of goals scored, the number of balls conquered with the observations on the balls retrieved at the front of the playing space by the observers.

The linking of these data provides a reliable evaluation of the actions in project and their results in order to re-animate the debates of ideas for the evolution or construction of new roadmaps. The teacher can also help in determining what is to be learned. In this way, it puts into perspective the elements to be observed, analyzes and regulates the roadmaps, and even encourages observers to observe more and more fine. The teacher is therefore not absent from the teaching/learning system because he also has his own roadmap. In all cases, this is to be compared with those of the actors who ultimately provide their own answer.

\section{Discussion}

This triangulation allows an indirect measure of the effectiveness of the debate of ideas. The practice of this debate nevertheless teaches us some precautions. This method allows students to learn how to develop a collective strategy through active methods. They observe, analyze, formulate problems, make hypotheses that the action has just put to the test. The observations help to structure the consultation and after this time of pooling, the actors show a capacity for reflection and regulation making the action more effective. The effectiveness of the team (the ratio of shots to the number of goals) appears very quickly as a trigger for collective consultation. The observation made collectively will generate reactions. Students describe and delineate observable manifestations. Relevant parameters (score, number of shots, number of goals conceded against counter attack) are recorded using the observation cards or subjectively. Collective dialogue will often focus on the dysfunction and insufficient performance of the team. Then the ideas of one and the other complement each other in order to emit collectively answers. Some students or a student more experienced than others, and then 
propose hypotheses for the rest of the game. His roadmap generally relies on changes in roles within the team. Regardless of their level of motor skills, students seem to possess many cognitive resources to solve the problems posed by the opposing team. It takes time; however, these resources do not appear right away. Students must get to know each other and identify the strengths and weaknesses of the group. First of all, all the work of the consultation consists mostly in putting into equation the motor qualities of the one and the others in order to exploit them to the best and to solve the problems rose. "You're the one who does this because you're fast and you're doing well". The difficulty then consists in consensually selecting the most appropriate answer and/or the one that brings together the most players. The questions posed strongly influence the types of verbalization, the positioning and the decisions of the players. Indeed, it is in the heat of the debate that students will build and develop reflexive activities on their own experience. Thus, they will generate practical and theoretical knowledge, but also know-how, skills, by privileging in this dynamics of exchanges, a process of co-construction and cooperation, more than submission. The expression and description of their own activity, the awareness of the knowledge they have acquired during learning situations, lead to a genuine appreciation and development of their skills.

This type of work emphasizes the time required for learning. In many researches (Berchebru, 2007; Zerai, 2006; Gréhaigne, 2009), it can be seen that it is from the sixth or seventh lesson that the results begin to evolve. Before, new answers emerge that require time to become stabilized responses; these are available as resources for the student in the upcoming cycles.

Then, one of the achievements of the research in didactics of collective sports in school is that the learning of a game cannot be conceived without an important practice. In discussing the problem of learning time, we emphasize that the recognition of differences in rhythm should now give each pupil all the time he needs to learn. Nevertheless, the opportunities offered to players still vary qualitatively in the way of actually reinforcing the "time invested in the task".

Finally, we will quote one of our colleagues after a cycle with a lot of play and debates of ideas "Beyond the results quantified, this descriptive can not communicate all the events, all the joys and all the debates that punctuated the cycle. How to transcribe the rare absences? How can we tell the reader that some of the pupils had no classes since morning and stayed to play? How do you explain that some played when they were physically diminished? The dynamics created around a cycle essentially based on gambling probably did not allow the weakest to transform radically. However the originality of this cycle has aroused great pleasure among the pupils and gave meaning to the lessons".

While verbalization is an important link in this type of teaching, it also has its limitations. Nothing can be done without the pupil taking real notice of the collective result to which he contributes individually. However, these indicators, however simple they may be, are not always met with the necessary attention. Taking clues by participating in the game, learning and asking for time. The 
student must first take note of the data to be taken (displacement, circulation of the ball...) and then get involved in the game. It must then appropriate the tool to quickly make the link between the action observed on the ground and the decision to be taken. Indeed, it is not always easy to play and observe at the same time. It thus seems essential to put two pupils (a script and an observer) to make the observations more reliable.

\section{Conclusions}

In this work, we try to show that we can develop and evaluate learning and learning strategies by using the verbal interactions of the players in the discussion of ideas. Playing collective sports means learning how to handle players' paths and non-uniform ball trajectories in emergency decision-making conditions in order to bring the ball into the area of the mark and score a point. For pupils, a real learning in collective sports games lies, in problem situations, to observe, to extract, to evaluate the information more and more relevant to reduce the analysis time, therefore decision to act in the game.

This reflection, based on a series of studies, focused on systematic observations of the game as well as on ways of organizing learning, considering that they could have an impact on a number of educational decisions and didactics. Nevertheless, it should not be forgotten that "the use of a strategy is always cognitively expensive in that it mobilizes attention to one or more of the different stages. It follows that the effort required must be felt by the subject (for us players) as justified and effective in relation to the aims pursued" (Fayol \& Monteil, 1994: p. 93).

\section{References}

Berchebru, M. (2007). Didactics of the Teaching of Collective Sports. When the Use of Multimedia Technologies and Verbalization Improves the Teaching of Team Sports. Masters' Dissertation, Besançon: University of Franche-Comté. (Unpublished)

Casetti, F., Lumbelli, L., \& Wolf, M. (1981). Indagine su alcuneregole di genereteleviso. Ricerchesulla communicazione. Quaderni semestrali dell'Istituto A. Gemeli Franco Angeli n³, Milan: Ikon, 11-122.

Chang, C. W. (2006). Towards a Constructivist Approach to Teaching Basketball in Taiwan. Thesis, Taipei: National Taiwan Normal University. (Not published)

Conquet, P., \& Devaluez, J. (1986) Design of Physical Education. In E.P.S Content and Didactics (pp. 91-103). Paris: SNEP.

Deleplace, R. (1979). Movement Rugby-Total Rugby. Paris: Physical Education and Sports.

Dugrand, M. (1985). Theoretical, Experimental and Clinical Approaches to the Teaching of Football. The Example in Senegal. Thesis, Caen: University of Caen.

Fayol, M., \& Monteil, J. M. (1994). Strategies for Learning/Earning Strategies. French Journal of Pedagogy, 106, 91-110.

Giordan, A. (Ed.) (1983). The Student and/or the Scientific Knowledge: Didactic Approach of the Construction of the Scientific Concepts by the Pupils. Bern: Peter Lang.

Gréhaigne, J. F. (Ed.) (2009). Around Time. Space, Learning, Projects in Team Sports. 
Besançon: Presses of the University of Franche-Comté.

Gréhaigne, J. F., Billard, M., \& Laroche, J. Y. (1999). The Teaching of Collective Sports Games at School. Design, Construction, Evaluation. Brussels: De Boeck. (Sport Sciences and Practices Collection)

Gréhaigne, J. F., Caty, D., \& Wallian, N. (2004). Authentic Evaluation and Balance of Power in Collective Sport. Measures and Evaluation in Education, 27, 25-39.

Gréhaigne, J. F., Godbout, P., \& Bouthier, D. (1999). The Foundations of Tactics and Strategy in Team Sports. Journal of Teaching in Physical Education, 18, 159-174. https://doi.org/10.1123/jtpe.18.2.159

Gréhaigne, J. F., Wallian, N., \& Godbout, P. (2005). Technological Approach and Didactic Modeling of Collective Sports at School. Impulse, 4, 59-79.

Jeu, B. (1977). Sport Emotion Space. Paris: Vigot.

Zerai, Z. (2006). How Do Girls Learn in Hand Ball? Contribution of Verbalization. Master's Degree in Physical and Sports Activities, Tunis: ISEFC.

Submit or recommend next manuscript to SCIRP and we will provide best service for you:

Accepting pre-submission inquiries through Email, Facebook, LinkedIn, Twitter, etc. A wide selection of journals (inclusive of 9 subjects, more than 200 journals)

Providing 24-hour high-quality service

User-friendly online submission system

Fair and swift peer-review system

Efficient typesetting and proofreading procedure

Display of the result of downloads and visits, as well as the number of cited articles

Maximum dissemination of your research work

Submit your manuscript at: http://papersubmission.scirp.org/

Or contact ce@scirp.org 